\title{
MONITORING TEGANGAN, ARUS, DAN DAYA SECARA REAL TIME UNTUK PERBAIKAN FAKTOR DAYA SECARA OTOMATIS PADA JARINGAN LISTRIK SATU FASE BERBASIS ARDUINO
}

\author{
Hidayat Nur Isnianto ${ }^{1}$, Esti Puspitaningrum ${ }^{2}$ \\ ${ }^{1}$ Program Studi Diploma III Metrologi dan Instrumentasi \\ ${ }^{2}$ Program Studi Diploma III Elektronika dan Instrumentasi \\ Departemen Teknik Elektro dan Informatika Sekolah Vokasi UGM \\ Jln. Yacaranda, sekip Unit IV Yogyakarta (55281) \\ email : ${ }^{1}$ hnisnianto@gadjahmada.edu, ${ }^{2}$ estipuspita@ugm.ac.id
}

\begin{abstract}
Electrical appliances in industrial and residential are now much inductive, consequently causing the power factor value less than 1 (one), so the power capacity installed to the customer is not optimal. Power factor improvements are needed to improve the efficiency of active power usage so that it can be maximized. To overcome this, a device is made to automatically improve the power factor due to inductive load changes, ie by installing capacitors in parallel to the source automatically using an Arduino-controlled switch when the power factor value is less than 0.85. The test results show that this power factor repair system is working automatically, real time and recorded on microSD. The power factor value can be up to 0.92 with $4.5 \mu \mathrm{F}$ to $18 \mu \mathrm{F}$ capacitors at inductive loads of $40 \mathrm{~W}$ to $225 \mathrm{~W}$ with error at $7.06 \%$ current sensor, $0.50 \%$ sensor, cos phi sensor $4.20 \%$. All measurements are displayed on the LCD and recorder on SDCard.
\end{abstract}

Keywords: inductive load, capacitor, power factor, sensor, arduino

\section{PENDAHULUAN}

Rumah tangga atau sejenisnya merupakan salah satu bidang yang mempunyai andil penting dalam peningkatan perekonomian masyarakat. Kebutuhan energi untuk keperluan rumah tangga saat ini semakin meningkat. Pemakaian daya listrik baik untuk kebutuhan rumah tangga pada saat ini mempunyai beban yang bersifat induktif. Dimana hal ini dapat menyebabkan gelombang arus tertinggal dari gelombang tegangan. Hal ini mengakibatkan besarnya daya yang diserap dari sumber lebih besar daripada daya yang dipakai oleh beban (faktor daya tidak maksimal), sehingga menimbulkan kerugian yang tidak sedikit.

Kerugian daya yang disebabkan beban induktif bisa dikurangi dengan daya reaktif yang dapat diperoleh dengan memasang rangkaian kapasitor (kapasitor bank) paralel dengan beban. Jika beban induktif ini berubah-ubah, maka daya kapasitif yang dipasang juga dapat berubah. Pada penggunaan kompensasi kapasitor pada beban induktif dapat meningkatkan efisiensi energi listrik.

Nagarajan dan Kandasamy (2012) membuat sistem untuk optimalisasi faktor daya menggunakan PIC yang lebih fokus pada metode pengukuran faktor daya untuk beban induktif dan belum divariasi dengan berbagai perubahan beban. Hasil pengukuran faktor daya ditampilkan pada LCD.

Shobha dkk (2016) membuat sistem perbaikan faktor daya berbasis Arduino dengan menggunakan simulasi tiga beban resistif, induktif, dan kapasitif yang tetap. Hasil yang diperoleh adalah adanya perubahan faktor daya menjadi lebih besar ketika ditambahkan kapasitor. Belum dicoba untuk beban yang bervariasi antara resistif, induktif, dan kapasitif.

Asha dkk (2016) membuat sistem perbaikan faktor daya berbasis PLC untuk beban 3 fase. Simulasi beban yang digunakan adalah motor listrik 3 fase, hasil pengukuran faktor daya ditampilkan pada LCD.

Aparna dkk (2015) membuat sistem perbaikan faktor daya untuk motor induksi 3 fase. Hasil pengukuran faktor daya ditampilkan pada LCD.

Solunke dan Mechkul (2017) membuat sistem perbaikan faktor daya berbasis mikrokontroler ARM 11 dan hasil pengukurannya ditampilkan pada LCD. 
Penelitian ini bertujuan untuk memperbaiki faktor daya pada jaringan listrik satu fase untuk rumah tangga secara otomatis, agar rugi-rugi yang ditimbulkan akibat beban induktif dapat dikurangi dengan cara menambahkan kapasitor secara otomatis pada jaringan listrik.

\section{BAHAN DAN METODE PENELITIAN}

Sistem monitoring tegangan, arus, dan daya secara real time untuk perbaikan faktor daya secara otomatis pada jaringan listrik satu fase berbasis Arduino memiliki blok diagram seperti pada Gambar 1. Sedangkan untuk diagram alir berkaitan dengan otomatisasi cos phi seperti pada Gambar 2.

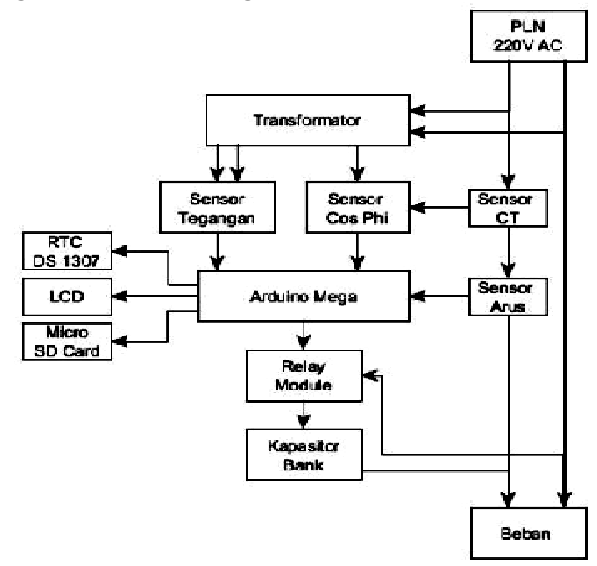

Gambar 1. Sistem yang direncanakan.

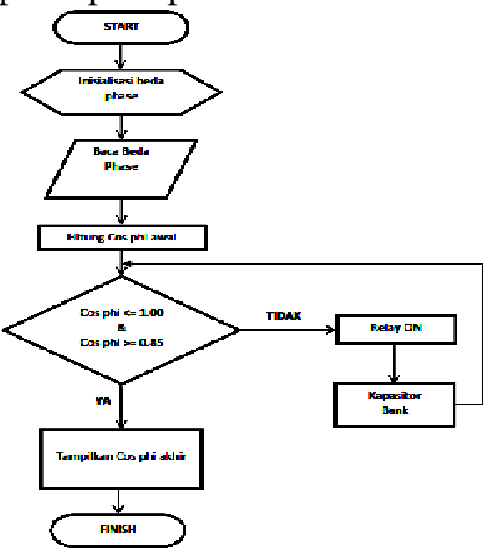

Gambar 2. Diagram Alir Sistem.

\section{HASIL DAN PEMBAHASAN}

\section{a. Pengujian Sensor Tegangan ZMPT 101B}

Sensor tegangan ZMPT 101B adalah sensor yang digunakan untuk membaca besaran tegangan AC pada jaringan listrik PLN. Hasil pengujian sensor tegangan ZMPT 101B seperti pada Tabel 1. Tabel 1. Hasil Pengujian Sensor Tegangan

\begin{tabular}{|c|c|c|c|}
\hline No. & $\begin{array}{l}\text { Hasil Pengukuran } \\
\text { dengan Alat Ukur }\end{array}$ & $\begin{array}{c}\text { Hasil Pengukuran } \\
\text { dengan Pembacaan LCD }\end{array}$ & $\begin{array}{c}\text { Faktor } \\
\text { Kesalahan } \\
(\%)\end{array}$ \\
\hline 1. & 2Bit & $\begin{array}{l}1: 201.4601+0,00 \\
P: 0.003 \text { PF:0,00 }\end{array}$ & 0,2 \\
\hline 2. & $\frac{{ }^{2024}}{69}$ & & 1,11 \\
\hline 3. & 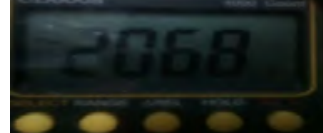 & $\begin{array}{l}\text { U:205.14 I:日, } \\
\text { P:0.008 PF:0. }\end{array}$ & $\mathbf{0 , 8 0}$ \\
\hline
\end{tabular}

Dari Tabel 1. diatas menunjukan pengukuran tegangan digital dengan alat ukur analog mempunyai faktor kesalahan rata-rata $0,70 \%$, sehingga dapat disimpulkan bahwa sensor tegangan ZMPT 101B dalam kondisi baik dan mampu bekerja sesuai yang diharapkan.

\section{b. Pengujian Sensor Arus SCT 013}

Sensor arus SCT 013 adalah sensor yang digunakan untuk membaca arus AC yang mengalir pada penghantar listrik yang menghubungkan beban dengan sumber tenaga listrik pada rangkaian. Hasil pengujian sensor arus SCT 013 dibandingkan dengan ampere meter analog seperti pada Tabel 2. 
Tabel 2. Hasil Pengujian Sensor Arus

\begin{tabular}{|c|c|c|c|}
\hline Beban & $\begin{array}{c}\text { Hasil Pengukuran dengan } \\
\text { alat ukur }\end{array}$ & $\begin{array}{c}\text { Hasil Pengukuran dengan } \\
\text { Pembacaan LCD }\end{array}$ & $\begin{array}{c}\text { Faktor Kesalahan } \\
(\%)\end{array}$ \\
\hline $\begin{array}{l}\text { Tanpa } \\
\text { Beban }\end{array}$ & & 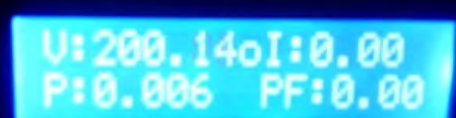 & 0 \\
\hline $\begin{array}{l}1 \text { Lampu } \\
\text { TL }\end{array}$ & & $\begin{array}{l}\text { U:202.170I:0.25 } \\
P: 20.89 \text { PF:0.34 }\end{array}$ & 11,63 \\
\hline $\begin{array}{l}3 \text { Lampu } \\
\text { Pijar }\end{array}$ & & $\begin{array}{l}\text { U:208.0 I:0.87 } \\
\text { P:180.86Pf:1.80 }\end{array}$ & 1,14 \\
\hline
\end{tabular}

Dari Tabel 2 menunjukkan bahwa sensor arus dalam keadaan baik. Pengukuran kurang dari 1A memiliki faktor kesalahan yang sangat besar, hal ini disebabkan alat ukur ampere meter tidak dapat dikalibrasi dan jika pengukuran arus diatas 1A mempunyai faktor kesalahan yang kecil. Pada Tabel 2 diatas mempunyai faktor kesalahan rata-rata 7,06\% saat berbeban dan $0 \%$ saat tak berbeban.

\section{c. Pengujian Sensor Cos Phi}

Sensor Cos Phi pada alat ini digunakan untuk mendeteksi faktor daya atau beda fase pada setiap sumber 220V AC yang diberi beban, baik beban induktif maupun resitif. Pada pengujian sensor Cos Phi dilakukan dengan menghubungkan PT (Potential Transformator) dan CT (Current Transformator) dari beban dengan rangkaian sensor Cos Phi yang terhubung dengan Arduino. Hasil pengujian sensor Cos Phi dibandingkan dengan alat ukur Osiloskop dengan beban resitif dan induktif dapat dilihat pada Tabel 3.

Tabel 3. Hasil Pengujian Sensor Cos Phi

\begin{tabular}{|c|c|c|c|}
\hline Beban & $\begin{array}{l}\text { Hasil pengukuran dengan } \\
\text { Osiloskop }\end{array}$ & $\begin{array}{l}\text { Hasil pengukuran dengan Sensor } \\
\text { Cos Phi di LCD }\end{array}$ & $\begin{array}{c}\text { Faktor } \\
\text { Kesalahan (\%) }\end{array}$ \\
\hline $\begin{array}{l}\text { Tanpa } \\
\text { Beban }\end{array}$ & 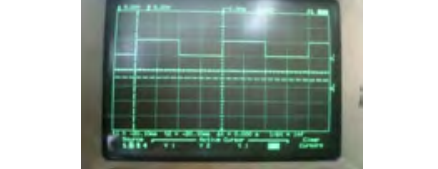 & 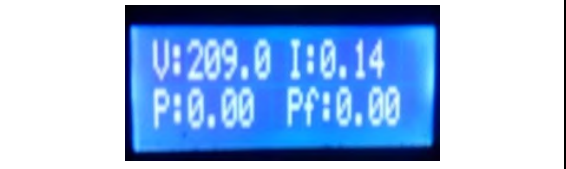 & o \\
\hline $\begin{array}{c}3 \\
\text { Lampu } \\
\text { Pijar }\end{array}$ & (1) & 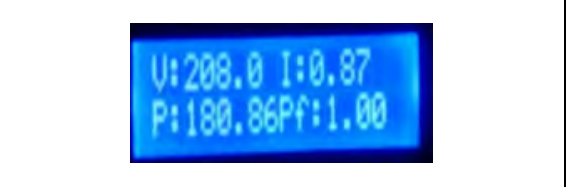 & 1 \\
\hline $\begin{array}{c}2 \text { Ballast } \\
\text { TL }\end{array}$ & D & $\begin{array}{l}\text { U: } 210,01: 0,63 \\
P: 10,70 P 9: 0,68\end{array}$ & 0,91 \\
\hline
\end{tabular}

\section{d. Pengujian Beban Tanpa Kompensasi Kapasitor}

Pengujian ini dilakukan dengan cara memberi beban yang bervariasi. Beban yang digunakan adalah beban listrik yang bersifat resitif dan induktif. Pada Tabel 4. Pengujian beban tanpa kompensasi kapasitor bank di tampilkan oleh LCD dan alat ukur berupa Osiloskop seperti pada Tabel 5. 
Tabel 4. Pengujian Tanpa Kapasitor

\begin{tabular}{c|c|c|c|c}
\hline Beban & P1 (W) & Q1 (VAR) & S1 (VA) & $\cos \boldsymbol{\varphi}$ \\
\hline 1 Lampu TL (40 W) & 46 & 26.07 & 52.87 & 0.87 \\
\hline 2 Lampu TL (80 W) & 95 & 133.43 & 163.8 & 0.58 \\
\hline 3 Lampu TL (120 W) & 140 & 218.24 & 259.3 & 0.54 \\
\hline 4 Lampu TL (160 W) & 186 & 305.5 & 357.7 & 0.52 \\
\hline 5 Lampu TL (200 W) & 230 & 377.8 & 442.3 & 0.52 \\
\hline
\end{tabular}

Tabel 5. Pengujian Dengan Kapasitor

\begin{tabular}{l|c|c|c|c}
\hline \multicolumn{1}{c|}{ Beban } & $\mathbf{P}_{\mathbf{2}}(\mathbf{W})$ & $\mathbf{Q}_{\mathbf{2}}(\mathrm{VAR})$ & $\mathbf{S}_{\mathbf{2}}(\mathbf{V A})$ & $\cos \boldsymbol{\varphi}$ \\
\hline 1 Lampu TL (40 W) & 46 & 26.07 & 52.87 & 0.87 \\
\hline 2 Lampu TL (80 W) & 95 & 46.02 & 105.6 & 0.92 \\
\hline 3 Lampu TL (120 W) & 140 & 59.65 & 152.2 & 0.92 \\
\hline 4 Lampu TL (160 W) & 186 & 90.1 & 206.7 & 0.90 \\
\hline 5 Lampu TL (225 W) & 230 & 111.25 & 255.5 & 0.90 \\
\hline
\end{tabular}

\section{e. Pengujian Beban dengan Kompensasi Kapasitor}

Pada pengujian ini sama dengan pengujian sebelumnya, tetapi disini adalah proses pengujian beban resitif dan induktif dengan mengkompensasi kapasitor. Pada Tabel 6. Pengujian beban dengan kompensasi kapasitor bank di tampilkan oleh LCD dan alat ukur berupa Osiloskop seperti pada Tabel 7.

Tabel 6. Pengujian Beban Tanpa Kapasitor

\begin{tabular}{|c|c|c|}
\hline Beban & Tampilan di Osiloskop & Tampilan di LCD \\
\hline 1 Ballast TL (20W) & 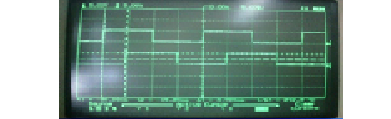 & 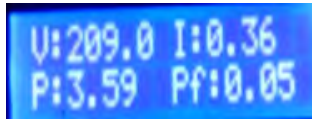 \\
\hline 2 Ballast TL + 1 Lampu Pijar (90W) & 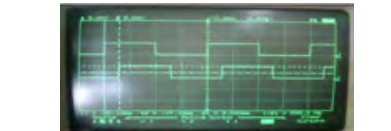 & $\begin{array}{l}\text { U:209,0 IH0,69 } \\
\text { PH88.37 PfH0,61 }\end{array}$ \\
\hline 3 Ballast TL (60W) & & $\begin{array}{l}\text { U:208.8 It8.92 } \\
\text { P:14.84 Pft0.88 }\end{array}$ \\
\hline
\end{tabular}

Tabel 7. Pengujian Beban Dengan Kapasitor

\begin{tabular}{|c|c|c|}
\hline Beban & Tampilan di Osiloskop & Tampilan di LCD \\
\hline 1 Ballast TL (20W) & $\sqrt{1}$ & $\begin{array}{l}\text { U:208.0 I: } 0.20 \\
\text { P:36.85 Pf:0.91 }\end{array}$ \\
\hline 2 Ballast TL + 1 Lampu Pijar (90W) & 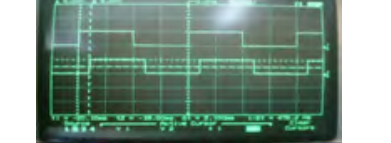 & $\begin{array}{l}\text { U:299.8 I:0.54 } \\
\text { P:94.92 Pft0.85 }\end{array}$ \\
\hline 3 Ballast TL (60 W) & $\operatorname{lin}_{1}$ & $\begin{array}{l}\text { U.259.8 I:0.54 } \\
\text { P:94.92 Pf+0.85 }\end{array}$ \\
\hline
\end{tabular}

Pengujian yang dilakukan pada Tabel 5. dan Tabel 7. faktor daya dapat diperbaiki secara otomatis dan mencapai nilai Cos Phi 0,85. Sehingga pada alat perbaikan faktor daya secara otomatis ini dinyatakan dapat berjalan sesuai dengan yang diharapkan. 


\section{e. Pengujian Micro SD Card}

Micro SD digunakan sebagai media penyimpan utama dalam perbaikan faktor daya secara otomatis. Dimana Micro SD Card akan menyimpan data pada pemakaian beban bertambah maupun berkurang berdasarkan waktu yang telah ditentukan, sehingga dapat mengetauhi histori pada beban. Histori pada beban dapat dilakukan dengan cara membuka file yang tersimpan pada SD Card berupa file data beban yang berubah ubah. Csv dapat dibuka dengan Microsoft Excel, sehingga dalam melakukan histori beban dapat dilakukan dengan lebih mudah dan dapat langsung di print. Adapun pengujian Micro SD dengan menggunakan Serial Monitor pada tampilan IDE Arduino ditunjukan pada Gambar 3.

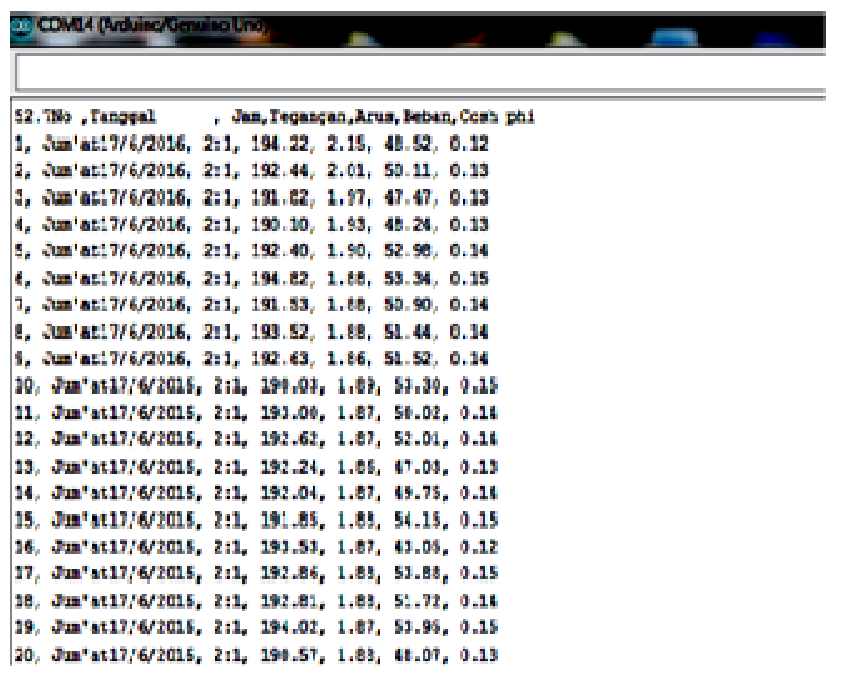

Gambar 3. Pengujian Micro SD Card dengan tampilan Serial Monitor

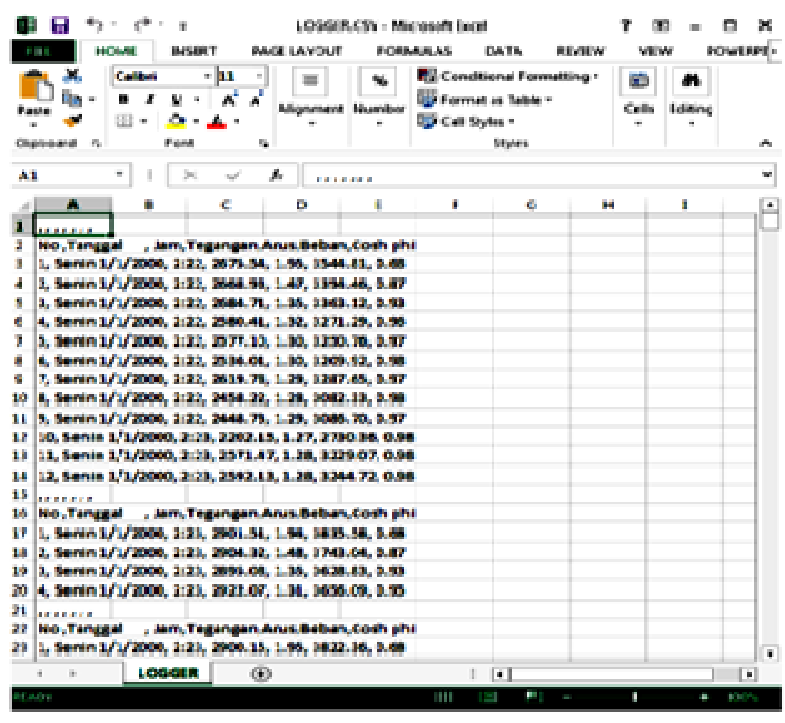

Gambar 4. Pengujian Micro SD di tampilkan ke Excel

Dari Gambar 3. diketahui pengujian Micro SD dengan ditampilkan melalui Serial Monitor Arduino. Format data csv yang disimpan pada Micro SD sama dengan yang ditampilkan pada Serial Monitor. Format csv tersebut dapat langsung dibuka pada Microsoft Excel sehingga tidak perlu melakukan pengeditan kembali. Format data yang disimpan pada Micro SD yang telah ditampilkan ke dalam format Microsoft Excel ditunjukkan pada Gambar 4.

\section{KESIMPULAN}

Setelah melakukan berbagai pengamatan, percobaan dan analisis terhadap perbaikan faktor daya secara otomatis pada beban induktif 1 fasa, maka dapat diambil kesimpulan sebagai berikut :

a. Sensor arus ACS 712 30A mampu membaca arus dari 0-30 A dengan error rata-rata 7,06 \%;

b. Sensor tegangan ZMPT 101B mampu melakukan pembacaan tegangan AC baik dalam kondisi berbeban maupun tanpa beban dengan faktor kesalahan rata-rata $0,5 \%$;

c. Sensor Cos Phi mampu melakukan pembacaan beda fase untuk beban induktif dengan error $4,2 \%$;

d. Alat yang dibuat dapat memperbaiki faktor daya dari 0.52 sampai 0.92 dengan kapasitor 4.5 $\mu \mathrm{F}$ sampai $18 \mu \mathrm{F}$ pada beban induktif $40 \mathrm{~W}$ sampai $225 \mathrm{~W}$;

e. Perhitungan waktu pada RTC DS 1307 mampu bekerja secara baik, hal ini memudahkan untuk dapat melihat history pada perbaikan faktor daya secara otomatis.

\section{UCAPAN TERIMA KASIH}

Dalam kesempatan ini, penulis mengucapkan terima kasih kepada Ginanjar Ahmad Santoso, Bagus Mulyo Tyoso, Rijeqi Rahmawati, dan Anisa Widya Sulistyawati yang telah membantu terlaksananya penelitian ini. 


\section{DAFTAR PUSTAKA}

Allegromicro. 2006. ACS712, Fully Integrated, Half Effect-Based Linear Current Sensor IC with 2.1 kVRMS Isolation and a Low-Resistance Current Conductor. Massachusetts : Allegromicro.

Aparna Sarkar, Umesh Hiwase, 2015, Automatic Power Factor Correction by Continuous Monitoring, International Journal of Engineering and Innovative Technology (IJEIT) Volume 4, Issue 10, April 2015, ISSN: 2277-3754, ISO 9001:2008 Certified

Asha Devi S., Anga Yazhini M, Gokul S., Bhuvanesh S., Logesh Prabhu V., 2016, Automatic Power Factor Control Based On PLC, International Conference on Explorations and Innovations in Engineering \& Technology (ICEIET - 2016) ISSN: $2348 \quad-\quad 8379$ http://www.internationaljournalssrg.org Page 63

Gonen, Turan. 1987. Electric Power Distribution Sistem Engineering. Singapore: McGraw-Hill Book Company.

Nagarajan M, Kandasamy KV., 2012, Optimal Power factor Correction For Inductive Load Using PIC, International Conference on Modelling, Optimization and Computing (ICMOC-2012), Procedia Engineering 38 (2012) 737-744, SciVerse ScienceDirect.

Shobha R.Mane, Ashwini A.Kolekar, Maithili M. Molaj, Sadhana V.Patil, Mazharhussain N. Mestri, 2016, Arduino Based Power Factor Correction, International Journal Of Electrical, Electronics And Data Communication, ISSN: 2320-2084 Volume-4, Issue-4, Apr.-2016

Stevenson. 1993. Power System Analysis. Singapore: McGraw-Hill Book Company

How To Measure Ac Current With An Arduino And An Asc712. Http:// Henrysbench.Capnfatz.Com/Henrys-Bench/Arduino-Current-Measurements/ Acs712-ArduinoAc-Current-Tutorial/. Diakses Pada Tanggal 1 Mei 2016.

Power Factor Measurement Using Microcontroller In Proteus ISIS. Http://Www. Theengineeringprojects.Com/2015/12/Power-Factor-Measurement-Using-Microcontroller-InProteus.Html. Diakses Pada Tanggal 1 Mei 2016.

Zero Crossing Detector Using OP-Amp, Http://Microcontrollerslab.Com/Zero-Crossing-DetectionUsing-Simple-Op-Amp/. Diakses Pada Tanggal 2 Mei 2016.

Ikhsan, Muhammad. Measuring AC Voltage Using Arduino: Maximum Voltage Method. Http://Sentroino.Blogspot.Co.Id/2015/12/Measuring-Ac-Voltage-Using-Arduino.Html. Diakses Pada Tanggal 5 Mei 2016.

EnergyMonitor, Trystan, 2012, AC Phase Control, http://openenergymonitor.org, diakses 8 Mei 2016. 